Journal of Management and Economic
Studies
2019, 1(4): 1-19 DOI: $10.26677 / \mathrm{TR} 1010.2019 .114$
Journal Homepage: https://www.jomaes.org

\title{
How do HR Professionals Negotiate Organisational Legal Compliance and Strategic Decision Making in Britain?
}

\author{
Kay Maddox-Daines \\ Acacia Learning Ltd, UK, Kay.maddoxdaines@acacialearning.co.uk \\ Danielle Wootton \\ University of Warwick, UK, daniellewootton@hotmail.co.uk
}

\begin{abstract}
This paper explores the relationship between compliance and strategic decision making from the perspective of senior HR professionals' professional identity. This research takes a multi case research approach across three public sector organisations; a primary Care Trust (PCT), a university and a local education authority in the southern England. In depth semi-structured interviews were conducted with 31 senior HR professionals. Template analysis was used to analyse the data. This paper argues that strategic decision making in the human resource role is limited due to the constraining influence that employment regulation has on workplace practices. The relationship between operational practices and strategy needs to be fully integrated if the human resource function is to provide an organisation-wide response. HR compliance and strategy are considered within the contemporary backdrop of increased employment regulation and the impact on human resource strategic decision making. The study explores how HR senior professionals position themselves within organisations and the relationship between strategy, employment regulation and professional identity.
\end{abstract}

Keywords: Human Resource Management, Professional Identity, Strategy, Leadership

\section{Introduction}

The role of HR has changed significantly over the last two decades, from an administrative to a strategic focus in order to maintain competitive advantage in response to globalisation and privatization of public owned companies (Anwar, 2016). The increased emphasis on the integration between human resource management and business strategy is one of the most important demands placed upon modern strategic HR (Hoor-Ul-Ain, 2014). Indeed, this shift to HR business role emphasises the value and need for aligning HR activities with strategic planning (Oppong, 2017). Yet, organisational business strategy is profoundly influenced by the complex context of resource decisions, decision makers norms and values, organisational culture, policies and the impact of the legal environment (Cooke and Saini, 2010). 
The increasingly regulated workforce arising originally out of the 1980s Employment Acts, but further developed by common law decisions, has provided specific challenges to HR professional knowledge base, and decision making. Before the 1980s in Britain there was little individual employment legislation in part due to the bargaining power of trade union movement. Now both the individual and collective employment relationships are subject to considerable complex employment regulation that has to be introduced and then subsequently managed within organisations. The human resource function is the natural home in organisations to implement new employment legal changes through policies and practices (Wootton, 2016).

Such changes usually manifest in organisational policy changes and advice in diverse areas such as recruitment and selection, anti-discrimination policies, and work place disputes, against the ever-increasing backdrop of potential employee litigation (Harris, 2009, Wootton, 2016) and role of "no- win no- fee solicitors". Notably, this was the case for Birmingham City Council where a class action for equal pay was won by workers. It predicted that it will cost the employer in the region of $£ 2$ million in total back pay (Churchard, 2012). The case (Birmingham City Council v Adbulla and others 2011, EWCA CIV 1412) was not brought by a trade union but by a firm of solicitors on a "no- win no- fee" basis, the firm being one of the many who have become more active in representing claims of workers (Wootton, 2016) which is now not an uncommon situation in Britain.

\section{Literature review}

Human resource professionals in the public sector have different forms of pressure from the private sector (Bach et al. 2009), due to having the state being the employer and the originator of employment regulation. For human resource professionals the relevance is that they have to manage key stakeholder relationships such as trade unions relationships, line managers and interactions with employees' legal representatives in a strong regulatory environment (Heery 2011a, Wootton,2016).

Importantly formalization of policies and practices, such as grievance policies, in the human resource function can be classed as a reaction to increased juridification alongside the impact of more tribunal decisions has undoubtably increased workloads within the function (Wootton, 2016). Yet, the law constantly changes notably in 2013 the Conservative Government brought in to law "The Employment Tribunals (Constitution and Rules Procedure) Regulations 2013"; which meant "Claimants who wish to bring a claim to the tribunal or appeal tribunal will have to pay a fee." (ACAS 2013). The situation changed again as in 2017 as the "The Employment Tribunals (Constitution and Rules Procedure) Regulations 2013" was overturned by a common law case brought in part by the British trade union Unison.

The impact on the human resource function is that policies and practices have to reflect changes in legal precedent with human resource professionals having to be able to understand the repercussions and then respond accordingly (Wootton 2016:45). Successive governments' usage of employment regulation to control workers' rights has resulted in human resource practices having to adapt to increased juridification (Harris, 2009); through policies and procedures inline with employment regulatory requirements. Often, the perception of organisational stakeholders such as line managers is that the human resource function and directors are there to restrict their activities not least due to the bureaucratic policies and procedures produced by the human resource function (Harris, 2009, Sheppard et al., 1992). Indeed, the devolvement of HR management to the line can further exasperate the relationship between HR and line managers. 
Yet, such devolvement can build line manager responsibility and allow HR to focus on strategic issues such as helping organisations to create value and achieve competitive advantage through the maximization of employee involvement and engagement (Armstrong, 2005). Organisational agility and HRM strategy both form crucial components in evaluating and strengthening the overall capability of an organisation's efficiency (Saha, 2017). Indeed, strategy and HR policy can have a positive effect on performance but this is dependent on the consistency of implementation aligned to the overall business strategy (Dogen et al, 2014). Participatory management, long term training policies, pro-active HR policies and generous compensation policies are more successful under a range of different strategies than dictating short term and ungenerous HR policies (ibid). Indeed, the implementation of policy is by no means straightforward when considering the importance of alignment to strategy, communicating content to stakeholders and ensuring consistent application. This is further complicated by the complex legal environment that $\mathrm{HR}$ professionals are required to navigate.

The degree to which HR professionals embrace the role of legal compliance officer, the further removed they become from strategic HR and true business partnering. As operational matters require urgent attention, short term priorities become the main focus for decision making. The positioning of the professional self is constructed through the ongoing process of relationships and this meaning is socially instituted and maintained through discourses (Butler, 2007). Indeed, over time people adapt aspects of their self to accommodate the demands of their job role, negotiating and adapting to the new situation (Ibarra, 1999:765). The actions of participants typically become patterned, anticipated and dependable (Weick, 2009) thus it becomes more difficult to reposition the self when hampered by the norms and beliefs of individuals and collectives in organisational life. This is important as who we believe ourselves to be is controlled to a degree through organisational rules in 'situ'. As a result when HR professionals assume the role of legal compliance officer it will be difficult to reposition oneself as a strategic partner.

Although much has been written about professional identity to date, much of this discussion has leaned towards a stage based, linear notion of progression (Priola, 2007) rather than insightful analysis of professional identity constructions in situ (Nicolini, 2012).Furthermore Wootton, (2016:39) asserts that, managing and understanding the issues relating to employment regulation has allowed the human resource function to create an organisational niche for itself by seizing the "opportunity presented by law to carve out positions within the business based on interpreting the law and ensuring compliance" (Heery 2011:80b). The difference now is increased juridification, which has required human resource professionals to have specialist knowledge to deal with legal issues, so raising the profile and status of the function in organisations (Wootton, 2016), Furthermore, there is little research that specifically relates to the professional identity constructions of senior HR professionals (Kinsey, 2012).

Professional identity develops over time, with varied experiences and meaningful feedback that allows people to gain insight into their central and enduring preferences, talents and values (McMichael, 2010). It can be conceived as, 'the relatively stable and enduring constellation of attributes, beliefs, values, motives and experiences in terms of which people define themselves in a professional role' (Schein 1978:20). Indeed, the concept of professional identity is important, as who people believe themselves to be influences what they do (Watson, 2006). This is important in that there is a strong link between professional identity and professional action and this is embedded within the relationships people hold within their organisations (Ibarra, 1999). In other words, how we are perceived and how we perceive ourselves will influence how we behave and what we do. 
Career curiosity and career concern enable HR managers to explore different HR functions and prepare themselves more effectively to play a strategic role in organisations. Career adaptability is an important aspect of career competence and a strong predictor of strategic positioning (Guan et al, 2016). Over time people adapt aspects of their identity to accommodate the demands of their job role and enact valued aspects of their identity to the new situation" (Ibarra, 1999:765). Yet, Guan's research highlights that professional identity negotiations are an integral component to success at the strategic level. These negotiations are largely made through the narratives that individuals engage in within the organisation context so that this provides the basis for understanding both shared and individual meaning, expectation and need (Weick, 2009).

Where insufficient care is taken, the sensemaking process will be less effective and this tends to be found in situations that lean towards interpreted representations that are 'correct' in the eyes or those 'making sense' (ibid). Yet, to effectively enable HR to balance its strategic goals and its transactional services HR need to build an effective partnerships with line managers. It is within these relationships that effective role positioning can be negotiated. Providing these managers with a better understanding of responsibilities in specific HR issues, i.e. absence control, team development, discipline, induction, health and safety, recruitment and performance management (Naznin and Hussain, 2016) will enable HR to focus more on employee engagement and change management and alignment of HR to the business strategy. Indeed, traditional HRM practices that are control orientated are often less successful than those that aim to empower and involve employees in decision making (Cooke and Saini, 2010).

Devolving HR management to the line is not without risk. Communicating and training line managers in HR policies is generally weak and many managers claim that they are not aware of policies in place (Anwaar, 2016). The implication is inconsistent application due to a poor level of understanding in the absence of communication and/or training (Stanton et al, 2010). A failure to understand cause and effect may result in a failure to recognize which behaviours to reward, leading to a lack of commitment, inconsistency and understanding. Indeed, the reality is that employment policy and regulation are tools to be utilized and the way that this is managed or mismanaged is down to the interaction between stakeholders and individuals; expertise (Dickens, 2012). Clearly, line managers require robust training and support to implement policy consistently and effectively (Cooke and Saini, 2010).

The regulatory environment coupled with the emphasis on human resource functions to focus on transformational strategic issues and the increasing devolvement of HR management to the line provide challenges to HR professionals in managing best fit between regulation and organizational practice. The onus is now on human resources (representing the employer) to ensure that compliance with the employment legal framework is adhered to throughout organisations in order to help prevent employee litigation (Dickens, 2012) whilst also balancing strategic goals. Indeed, HR activities (legal and otherwise) considered in isolation mean little to the strategic direction of the HR department (Oppong, 2017). Consequently, the responsibility lies with human resource departments to cover the back of the employer against legal claims; this in turn has led to more formalized stakeholder relationships in order to prevent financial repercussions to the employer and these are rooted in compliance led practice.

\section{Research aims and objectives}

This paper explores how senior HR professionals translate regulation into policy and practice and the extent to which they manage transformational HR in association with devolvement of HR management to the line. Indeed, the application of HR in context is "critically dependent on 
the mediating role of managerial and professional groups within and across organisations who interpret the law and formulate standards of compliance." Heery (2011:80).

The complexity and growth of employment regulation has had a positive and negative influence on the human resource function and profession (Dobbin and Sutton, 1998:470). Firstly, by being managers of the policies and procedures relating to employment regulation, human resource professionals fulfill a professional gatekeeper role, or an important first line of defence, to incoming employment regulatory demands. Secondly this has created negative repercussions in that employees can view human resource professionals as being rule book enforcers, not strategic decision makers (Wootton, 2016).

Further exploration of professional positioning is required to get a sense of how these professionals negotiate role possibilities in the relationship between strategic decision making and the legal environment. Career curiosity and concern (Maddox-Daines, 2015) will be examined in supporting HR professionals to navigate regulation into organisational policy, practice and leadership in organisational contexts and the implications of compliance related decisions on business strategy will be considered.

Aims

The paper seeks to identify the theory and practice implications relating to how managing employment regulation at an organisational level has influenced HR strategic decision making.

Research questions

(1) how does employment regulation influence HR professional strategic decision make?

(2) what is the relationship between senior HR professional identity and the regulatory environment?

(3) what are the practice implications for senior HR professionals when making strategic decisions against a background of increased employment regulation?

The epistemological position taken in this research project is interpretivism. There are many different types of interpretivism but "common to all of these is a concern with subjective and shared meanings" (Eriksson and Kovalainen, 2008:19) and language. The emphasis in interpretivism is on understanding people's attitudes rather than viewing them as objects. The rationale for the interpretive nature of this study is that the researchers and the social world impact on each other, there is not a distant relationship between the research and the researchers. This constructionist approach emphasises and values social interaction with stakeholders.

The research approach taken for this study is qualitative. Denzin and Lincoln (2005: 3) observe that "qualitative research involves an interpretive, naturalistic approach to the world. This means that qualitative researchers study things in their natural settings, attempting to make sense of, or interpret, phenomena in terms of the meanings people bring to them." The justification for taking a qualitative approach to designing, collecting and analysing data in this research was the need to collect data that is both rich (Robson, 2002) and meaningful rather than collecting standardized data through quantitative approaches (Saunders et al, 2009).

The study employs an inductive framework, thus supporting the collection and interpretation of the data collected. This type of research is commonly used in research involving case studies (Saunders et al, 2009). Yet, Bryman and Bell (2007:15) note that the distinction between 
inductive and deductive research is "often better thought of as sequences rather than as hard and fast distinctions". The research framework is outlined in more detail below.

\section{Method}

This research takes a multi case research approach across three public sector organisations; a primary Care Trust (PCT), a university and a local education authority in southern England. The case study organisations in this research granted access on the basis of confidentiality agreements between the researcher and the organisations. This study required an organization context because the relevant professionals generally work within organisations, and this is where the professional has its bedrock.

Semi-structured interviews were conducted with 31 senior HR professionals (Bryman and Bell, 2007). Template analysis was used to analyse the data (Waring and Wainright, 2008) allowing a certain degree of fluidity in the establishment of ordered relationships between the themes.

This project interviewed participants from three public sector organisations which allowed an opportunity for comparison. Yin (2004) points out that one of the advantages of using case studies is that if there are some issues with one case study (such as insufficient data for some of the research questions) there are the other cases to provide meaningful data. Using more than one case study enables the researcher to compare responses, thus giving a more in-depth and valid understanding of the subject matter.

In this paper the decision was made to try to obtain as much access to interviewees

in medium to large public sector organisations as possible. Once access was obtained, the organisation's representative supported access to the relevant participants. The case study organisations are protected using replacement names in health, local government and education (detailed in table 1).

Table 1: Case Study Organisations used in this research

\section{Health}

The backdrop for the health case study is a Primary Care Trust (PCT) in a large urban area. The organisation is responsible for improving and maintaining the health of their local population and the PCT board is made up of executive and non-executive directors, including members from the Professional Executive Committee. The human resource management department is part of the professional directorate and is led by a director of human resource management, who has the responsibility to develop and drive the strategy within the whole of the workforce of the PCT.

\section{Education}

A further case study is based on a university, which operates from a purpose built campus focusing on research, teaching and enterprise. The University has several internationally recognised research faculties where student numbers have grown to substantial undergraduate and postgraduate intakes of national and international students. The human resource management department, led by a human resource director who has responsibility for all strategic, operational and personnel issues, is part of the University's professional administrative support service. In the human resource team, the director is supported by three other directors who help to manage the various divisions within the function in relation to people-related matters. There are over 150 members of the human resource team comprising managers and assistants. The human resource management department is represented in all the 
University faculties. Furthermore, the human resource function is also represented, usually at office level, as a devolved service within the separate University academic and service functions.

\section{Local Authority}

The third case study is based on a local government organisation in southern England. The human resource management function has the following teams: Organizational Development \& Training, Recruitment and Retention, Personnel Services, Business Support, and, Payroll and Pensions. Participants, including the human resource director, were interviewed from all sections except payroll and pensions. The service was not decentralized and operated from one location.

In total 31 participants were interviewed across all three case studies in this research. Their job roles included human resource directors, human resource managers, trade union officials and line managers (please see appendix 1 for a summary of interview questions).

Template analysis was used to make sense of the data gathered. This approach is recognised as a relatively new method in data analysis in business research. Waring and Wainright (2008:1) argue that it has "emerged from more structured approaches such as Grounded Theory and Interpretative Phenomenological Analysis (IPA)." The decision to use template analysis as a research method was based on its flexibility. As King (2006:268) states: "the term template analysis does not describe a single, clearly delineated method; it refers rather to varied, but a related group of techniques for thematically organising and analysing contextual data." King (2006:268) argues that some templates are "too simple to allow any depth of interpretation, or (more often) too complex to be manageable." The template in this research was constructed using the software program NVivo (Gibbs 2002). After the initial template had been devised a further period of modification enabled the researcher to impose more structure on the template, thus developing a clear path between theory relevant to this research and data analysis.

\section{Findings}

There has been much discussion (Boxall and Purcell 2008; Legge 2005; Kochan et al, 1986) regarding the importance of the human resource function aligning itself with the strategic direction of the organisation, thus raising the role of the human resource professional as a strategic actor (Bacon 2003:76-77). However, this relationship has not been fully analyzed in relation to strategy formulation. As Dibben et al. (2011:97) point out, strategic models assume "that strategy formulation is a straightforward process and that managers in fact have a degree of choice with which they credited." Yet, the findings in this study reveal the complexities of aligning and balancing strategic and operational priorities.

Research Q1

How does employment regulation influence HR professional strategic decision making?

Despite acknowledging the need for a human resource strategy, participants in this study either were not aware of a plan or else found that the organisational drivers provided the required steer for HR activity.

Vignette 1

"We haven't got one here (human resource strategy). We have an organisational plan ... it has to be in the broadest terms due to it being a public sector organisation which is subject to Government changes" 


\begin{tabular}{|l|}
\hline (interviewee 1) \\
\hline "We need to start with what the organisation is trying to achieve" (interviewee 19) \\
\hline "Not sure there is a formal strategic human resource? It is more about understanding the culture and \\
relationships." (Interviewee 21)
\end{tabular}

Stakeholder relationships and organisational culture have a strong influence on shaping HR priorities but this may encourage HR as a follower rather than a shaper of plans. Indeed, the HR Director in the Local Authority estimated that customers and service heads appreciated most the transactional activity that accounts for about $60 \%$ of HR work and case work that accounts for about $30 \%$ of activity. Therefore, the $10 \%$ attributable to strategic development is either not known, not understood or not appreciated.

In the absence of a formal HR strategy to drive the organisational plan the legal framework often intervened to provide the required steer for HR activity.

Vignette 2

"Organisational, leadership capacity and skills are strongly impacted by the legal framework" (interviewee 4)

"Pay and reward is affected by legal considerations that in turn affect strategic decisions" (Interviewee 1)

"Legislation has such a large impact on the recruitment process or parts of legislation it's important to be updated and keep updated in order to make sure we are running the best service possible" (Interviewee 3)

Strategy tended to be formed 'in action' and retrospectively rather than in a systematic and planned response in relation to the organisational objectives. This is in part due to the nature of the sector and the short-termism present in decision making aligned to the political agenda.

Vignette 3

"I think there is a steer that the legislation does guide our strategic Moves" (Interviewee 1)

"At times certain things would not be happening unless it was legally Directed" (Interviewee 20)

"Strategically I would have to say you would need to consider employment law and I think human resource needs to be part of strategic planning and the business plan" (Interviewee 21)

\section{Research Q2}

What is the relationship between senior HR professional identity and the regulatory environment?

The degree to which the professional identity of the HR professional is influenced by the regulatory environment was found to be strong in this research. HR activity is generally assessed by internal measurables and these may influence the work undertaken. What is valued by the organisation may drive the prioritisation of HR work.

Vignette 4 
"I think also we can't forget the transactional processes, as you are so judged on how effectively you can turn a contract round" (Interviewee 19)

'"because we are public sector it's important we comply ... we are role models if we get it wrong then everybody knows about it and the papers love it if we get it wrong"(Interviewee 3)

"But you do become embroiled in following the various policies, following the various procedures, dealing with the calls from the union who are involved in terms of the legalistic queries and there is a danger that you lose sight of what is the real issue" (Interviewee 14)

Clearly, the reputation of an organisation is key and will ultimately impact on both internal and external measurables. As a result policy adherence and process governs prioritisation of HR tasks. Operational tasks rise in importance due to stakeholder influence and time orientated pressures. Stakeholder perception of what the HR function does/should do will impact on the work it does and the importance attributable to various tasks and roles.

Vignette 5

"I think it is a really big role - every day you are referring to some sort of law and in every case you have got you are thinking, in the back of your head... if this goes to an employment tribunal, how do we need to make sure we have covered our own backs as it were, to make sure there isn't a case to answer to an employment tribunal, so every situation we are in... It's like a defence system, how do we defend ourselves against action really, so how we cover our own backs, protect ourselves" (Interviewee 24)

"You have to be good at the procedural side (etc).Generally whatever your view is on human resource there will always be operational human resource, that is the strength of the service and employment law is what it is about" (Interviewee 26)

The threat of things going wrong and ending up in an employment tribunal impacts on the way HR manage their role. For interviewees in this research the procedural element of the function is key and the advice regarding how to follow process is a substantial part of the role. The HR teams appeared to spend much time in managing calls regarding service delivery, supporting managers in understanding and following policy and intervening when things went wrong. Little time appeared to be spent on developing managers in policy compliance and following process, training managers in handling difficult conversations and standard case work.

The views across the case study organisations emphasised the increasing influence of employment regulation on decision-making, both in having to defend against potential litigation and by influencing stakeholder communication. This was particularly felt by those that had worked in the profession for some years, developing in their role from administrative support officer to specialist legal advisor.

Vignette 6

"People will come to us for legal advice on employment matters yes we are that legal hub" (Interviewee 4)

"Law's creating problems and conflicts in the workplace. Encourages petty behaviour, and our job role is to sort it out. Sometimes moves cases to the end result and too quick to litigate" (Interviewee 20)

"They see us as legal advisors; they tell me they love me. Common sense what we say not rocket science it has an impact in terms of reassuring giving the confidence in what they do. Human resource as catalysis 
we set the legal framework, we would explain the legal context, then give them reasonable employer response" (Interviewee 1)

"We have to give legal views and expertise at all levels and people [line managers and employees] recognize that whether they like it or not"(Interviewee 26)

Becoming the legal hub, sorting out problems and conflicts, explaining the 'rules' to line managers and offering advice across the hierarchy are key role descriptors identified by interviewees in this research. These activities tend to be reactive in line with the short term needs of stakeholders. Responding to ad-hoc needs and requests prevents a planned and systematic approach to HR work. Participants in the health organisation emphasised a reactive approach to employee disputes and their desire to avoid tribunal appearances, giving the impression that legal activities are a significant influence on the human resource management's day-to-day operational work. This case study revealed considerable pressure from employees asserting their employment rights, more so than in the other two cases studies.

\section{Research Q3}

What are the practice implications for senior HR professionals when making strategic decisions against a background of increased employment regulation?

Human resource professionals in this research see employment regulation as part of their professional skill set and this influence impacts on stakeholders relationships and the way in which HR is perceived within the organisation. Indeed, research participants from across the case studies indicated that employment legal advice forms an integral part of their relationships with line managers, especially in the areas of anti-discrimination policies and practices.

Vignette 7

"You often get comments like well I suppose we ought to run this by you, or you are probably going to say no, but they think human resource role is blocking what they want to do. I think the relationship is getting better with managers, I think at first they just thought human resource was something to get in the way but I think more and more people are starting to come to us and they do on the whole accept what we say, and they are starting to learn and understand that the law does impact"

(Interviewee 22)

"Not that they necessarily understand the law around discrimination, when it comes to harassment casework, and I am not sure that they understand about constructive dismissal" (Interviewee 21)

"Yes, because it makes you indispensable. They need to come to us because they can't do it. The managers can't deal with the situations without our help"

(Interviewee 11

Research participants emphasised their 'expert status' as employment legal advisors. They felt that managers are increasingly dependent on them either because they find employment regulation too complex, or because they do not have the time to keep up-to-date with the relevant employment legal requirements in areas such as discipline and recruitment. The Director of HR in the higher education institution considered that human resource professionals are legal advisors and ultimately problem solvers for managers. 
Vignette 8

"Dealing with legal requirements has had a big impact on my role as head of human resource management overseeing the operational human resource team, with personal involvement in the complex or very sensitive areas impacted by regulation and the impact of tribunals" (Interviewee 26)

"Line managers expect human resource to be advisers and navigate them through issues and advise professionally where the needs of the business can be assisted within the confines of employment law" (Interviewee 20)

"The perception of human resource professionals, it has to change, and this will be done in how we manage line managers and our own personal relationships. They have to know that they are getting expert advice" (Interviewee 22)

"It is easy in an operational role to lose sight of the business, can be insular in what you are doing -must have a wider knowledge" (Interviewee 21)

Research participants in this study discuss employee relations interchangeably with other HR practice, rather than identifying this area as a core component in the overall HR agenda. The demands of employment regulation were frequently mentioned by participants from all the case studies although there was a disjointed understanding by research participants as to what constitutes human resource legal compliance. Furthermore, human resource professionals in this research make little distinction in terms of employment regulation between what Boxall and Purcell (2008: 74) define as the "micro and macro" best practice models. This research found that there is an absence in the debate between human resource "best practice" and "legal good practice guidance" and how these were understood in terms of human resource strategic "best practice"

The time and resources dedicated to support employee relations impacts on the extent to which HR professionals are able to focus on strategic work. This research found that employment regulation restricts the ability of human resource professionals to impact the organisation through human resource strategic decision making ability (Legge, 2005:160). Indeed, the human resource directors from the health and local government case studies agreed that their strategic decisions (choice) were impacted due to the potential repercussions of not giving the right legal advice, or the impact of employment tribunal cases.

\section{Conclusion}

The case study organisations in this study reveal a fundamental shift in the work of HR practitioners: from generalist HR advisor to employment law specialist. This was consistent across all three case studies. This shift has implications for the HR professional as a strategic practitioner whilst simultaneously impacting on the professional identity constructions of senior HR staff. These factors combine to influence heavily on the practice based decisions that HR professionals make when navigating an environment steeped in employment regulation.

Research Q1

How does employment regulation influence HR professional strategic decision making?

In this research it is noted that there is a discrepancy between legal management practice, stemming from case law (legal practice guidance) and work associated with strategic human resource management. Moreover, human resource professionals frequently link good legal practice originating from legal judgments with best practice approaches. 
Even though many of the participants talked about the role of strategy in relation to how human resources had increased value and status, they could not identify what they were doing in practice that was directly strategic. There appeared to be a lack of awareness of the extent to which regulatory pressure was influencing the future development of the human resource function (Cooke and Saini, 2010).

Strategic decision making is a problematic area in employee relations as there are many unknowns and external influences that are out of the control of the human resource function, yet a key strength of the function lies in sound operational practices. The relationship between operational practices and strategy needs to be fully integrated if the human resource function is to provide an organisation-wide response through practices in order to comply with increased future employment regulation whilst simultaneously supporting the organisational strategic objectives (Saha, 2017). Yet, in this research the HR strategy was not always clear, nor pragmatically understood impacting on the efficiency of the organisation. Indeed, the HR time spent reacting and complying with the legal framework had a direct influence on their ability to drive forward good practice in resourcing and managing talent.

The role of the legal context, directly or indirectly, is not specifically factored into strategic decision making which does not take into account the effect of employment disputes on strategic decision making (Bacon 2003:81). Research participants discussions regarding the relationship between strategy and employee relations did not overtly address the indirect effect that employment regulation has in constraining the strategic ability of the human resource function in making decisions.

An underdeveloped understanding of how strategic decision making is altered by disputes in the employment relationship was uncovered in this study, particularly as participants in all three case studies noted the direct effects of employment tribunals on day to day activities (Dibben et al. 2011). In particular, participants pointed out issues relating to resourcing implications, such as the time human resource professionals spent on updating knowledge, in negotiating with trade union representatives, and in giving advice to other stakeholders. They gave examples of how they were trying to prevent something going wrong rather than proactively trying to change employee working conditions through positive compliance. As Wootton, (2016:194) found "regulation enhances human resource practices by acknowledging the role legal implications have on the strategic objectives of the function", with resourcing both time and training having higher legal resourcing implications.

The human resource function has the potential to be strategic but this research finds that this point has not yet been fully realised largely due to HR's focus on legal positioning in the public sector (Harris, 2009). The strategic ability of HR to successfully operate beyond the requirements of the regulatory environment in the bigger organisational picture is largely constrained by the limits placed upon HR professionals by themselves through the work that they prioritise and the role identity they negotiate (Watson, 2006). But this process results in both exclusionary and inclusionary practice, whereby HR are keen to raise their profile through their expert status in employment law but simultaneously this excludes them from the strategic focus (Maddox-Daines, 2015).

In other words, there needs to be greater consideration given to how employment regulation interacts with "humans resource strategic agility" (Guest, 1987a) and the broader legal framework, in order to influence strategic decision making. In particular the role of ", antidiscrimination legislation, the contract of employment and tribunal procedures impact on how flexible the human resource function can be in delivering a strategic agenda" (Wootton, 2016:231). 
Research Q2

What is the relationship between senior HR professional identity and the regulatory environment?

There was recognition by many of the research participants across all the case studies in this study that employment regulation has not only changed their working environment but has also changed human resource management's professional and organisational roles, due to a "no-choice" reality of implementing employment regulation in organisations. The feeling of being maneuvered into a particular position suggests a surrendering of identity towards the needs of the role 'in situ' (Nicolini, 2012). A perception of less power in strategic discussions led to personal positioning and control. The desire for affiliation through expert status rather than a strategic voice resulted in role negotiations to elicit new connections (Maddox-Daines, 2015).

Providing expert advice to avoid discrimination claims is just one example discussed by participants in this study. This research found at the root of this omission the lack of distinction between expert advice and legal practice (skills) - professional jurisdiction boundaries do not differentiate between expertise and practical skills in order to be classed as a professional.

The quality of interpersonal relationships that human resource professionals develop with line managers is recognised as important for the consistent application of policy and adherence to the legal framework. Yet, behind this reasoning there appears to be some motivation and desire towards the re-negotiation of the HR generalist role to one which requires employment regulation expertise and a role which commands greater importance, respect and prestige within the organisation (Anwaar, 2016). This is in stark contrast to earlier debates relating to the degree of HR work that should be devolved to the line (Watson, 2006).

This research found that human resource professionals are pragmatic interpreters of law; in other words, their strength and status is based around policies and procedures. This is particularly notable regarding specialist knowledge when interpreting common law in relation to tribunal cases (Wootton, 2016). Illustrating that, HR is carving out a new role within the case study organisations in this study, enhancing its status and positioning and this professional identity evolution is socially constructed through stakeholder dialogue (Butler, 2007). This requires different skills of 'career competence' which impacts further on strategic positioning (Guan et al, 2016).

Line managers increasingly require HR support and HR are working hard to ensure that they are seen as credible. There is a desire for "status and respect" and some attempt to exert power and control over stakeholders within the organisation so that line managers feel obliged to "check in" with HR prior to making people management decisions. Yet, this aspiration simultaneously reinforces perceived identity as individuals come to specify themselves through monolithic discussion of what constitutes identity within the revised parameters set (MaddoxDaines, 2015). The reality is that human resource professionals are an important front-line defence, working in partnership with line managers against potential litigation, but their role is dependent on how their expertise is recognised and used by line managers. This research concurs with Dibben et al. (2011:231) in that more formal policies and practices stemming from a legal framework have increased the status of human resource professionals in organisations. This is because the requirement for legal compliance has meant that individual line managers needed human resource help more as the latter had greater expert knowledge regarding law.

Yet, this does not appear to be just a reactive response to the strategic demands of the organisation and the needs of line managers, instead an increasing number of HR professionals have purposely started to rebrand themselves as a service offering legal support. Repositioning 
takes time and the degree to which the HR function's impact is measured will influence the repositioning that takes place (Weick, 2009). This position appears to conflict with the fact that there appears to be an increasing expectation by organisations that line managers will take on an increasing level of legal responsibilities (Armstrong, 2005).

It was apparent in this research that human resource professionals had some reluctance to devolve responsibility to line managers, not just because there was concern over competency, but also because there appeared to be a form of bureaucratic protectionism, with the human resource function attempting to maintain its status. This approach will not diminish the workload of the department and may subsequently reduce the confidence and desire of line managers to effectively manage less complex case work. There appears to be a 'form of social $\operatorname{code}^{\prime}$ (Andrews et al, 2008:7) that shapes the professional identity not just of individuals working in HR but the whole HR function within organisations (Maddox-Daines, 2015).

Additionally, the extent to which HR professionals position themselves as legal advisors and compliance officers within their organisation may constrain their ability to act as strategic HR partners. The success of the evolving identity depends on the ability of the of the individual to continue and embed a consistent storyline (Loxley, 2007). The operational nature of compliance impacts on the time available for mapping and evolving HR policy and practice with strategic organisational objectives and intent. Although knowledge of the legal framework is an integral part of the HR role, being perceived as the expert in employment legal knowledge may impact on the degree to which the organisation embraces HR as a true strategic partner as operational day to day matters take precedence (Weick, 2009). In considering the relationship between strategic HR and legal compliance, participants reported a mixed response on the influence of each.

\section{Research Q3}

What are the practice implications for senior HR professionals when making strategic decisions against a background of increased employment regulation?

Case study organisations in this study used standard benchmarks that were produced as monthly or quarterly reports to measure HR performance. Performance indicators included absence figures and tribunal appearances, all of which were made available to the wider organisation. These performance indicators are used to judge the success of the function along with how line managers are complying with policies and procedures in areas such as sickness absence. All case study organisations found that measurements of success were indeed hard to measure particularly because performance indicators do not measure the exact time and methods spent on individual case work. Performance indicators influenced HR work priorities thus encouraging an operational and reactive focus rather than strategic positioning to support organisational objectives and development.

The absence of an HR strategic plan and internal organisational performance measurables encouraged an operational focus of HR professionals in this study. Strategic work appeared to be limited to the remit of directors. The director of HR in the health organisation identified a natural progression from operational to strategic decision-making in career development but was unable to clarify when operational decision making becomes strategic. The director also noted that the operational work undertaken by the HR department did not support HR professionals' strategic understanding of the organisation. HR professionals received feedback and recognition for their legal expertise thus encouraging further investment in this activity to secure belonging (McClure and Brown, 2008). The way in which HR work is structured impacts on the extent to which HR professionals are able to engage with strategic HR decisions. In the health organisation the operational function (i.e. employee relations) is split from the strategic 
work of the human resource function (namely workforce development). The HR director in the local government organisation similarly acknowledged that employee disputes came under the operational focus and strategic work, consisting of future workforce planning was structured separately. This work structuring appears to support boundaries and exclusions (MaddoxDaines, 2015) and ultimately denies those specialising in legal work to position themselves strategically.

The director of HR in the education organisation considered that HR strategy is strongly influenced by the organisational environment and what the organisation is aiming to achieve. Although there was a pressure to be legally correct, employment law compliance did not provide the focus or starting point for strategic HR planning. In this organisation strategic and operational HR activity was not separated so that sensemaking occurs with others in mind (Watson, 2006), providing the basis for development and understanding in strategic decision making. Senior HR professionals under director level tended to consider the legal employment framework as the dominant factor influencing HR strategy.

The separation of operational and strategic HR activity does not prepare HR professionals for career development, neither does it support the integration of organisational goals into operational practice. Strategic decision making is a problematic area in employee relations as there are too many unknowns and external influences that are out of the control of the human resource function, yet the strength of the function lies in sound operational practices and not hankering after strategic recognition unless it links directly to operational practice. The relationship between operational practices and strategy needs to be fully integrated if the human resource function is to provide an organisation-wide response through practices in order to comply with increased future employment regulation (Wootton, 2016).

Yet, there appears some appetite for ensuring "strategic flexibility" in order to support possible workforce reductions. Although formal HR strategic plans were not in place there appeared to be clear evidence of "a sense of direction" at the very senior level. The rationale for not formalising the plan was to ensure that any government changes or $u$ turns could be managed in a short space of time. Keeping a plan in the broadest sense ensured the highest degree of flexibility to make changes in a short space of time. Yet, this stance may indirectly increase vulnerability as HR professionals seek out a position to secure their tenure in an uncertain environment (Maddox-Daines, 2015).

This research found that there are differences in how human resource professionals who work at a level below the human resource director interpret strategic decision making. Whilst they understand the importance of good day to day operational practices as essential for performing their role, they were less able to define this work in relation to organisational strategic objectives. Even though many of the participants talked about the role of strategy in relation to how human resources add value, they could not identify what they were doing in practice that was directly strategic. In particular, participants pointed out issues relating to resourcing implications, such as the time human resource professionals spent on updating knowledge, in negotiating with trade union representatives, and in giving advice to other stakeholders yet they did not see such work as strategic. Yet our research found that employment regulation had an impact on human resource strategic decision making as employment regulation (Dickens, 2010) not only imposes budgetary constraints, but also affects management style and the freedom to manage employees. This is significant because if employment regulation is prioritised over strategic direction this will impact on the vision and goals of the organisation.

Participants emphasised the time consuming and exhausting nature of contractual work which prevents them from getting involved in anything more proactive. Employee relations issues consume all other HR activity; legal enforcement prevents HR development and limited 
resources impact on project work such as developing talent pipelines through online recruitment systems. This in turn, may impact on the added value offered by the HR team and at the extreme, encourage withdrawal and protective stances (Bullough, 2005) which limit the skills development of this group, impact on the strategic development of the organisation and contribution to attrition levels. There appears to be an enduring gap between the rhetoric and reality of strategic HR in the case study organisations largely due to the extent to which HR professionals are tied up with legal compliance issues.

HR transactional activity was found to be particularly valued by stakeholders in this study. HR priorities were influenced and defined by the needs of stakeholders coupled with organisational performance indicators. These measurables provide a sense of what is considered important to the organisation and tends to encourage a reactionary pressure to focus on short term targets.

The lack of involvement and as a consequence, understanding, of strategic HR limits the possibilities for career advancement in HR. With a lack of exposure and opportunity to get involved in HR strategic work, HR professionals are unprepared for directorships and senior HR roles. Yet, the HR professionals in this study appear to be carving out a new identity, away from the generalist HR advisor to one which requires more specialist skill, as employment law advisor. This role rebranding attracts greater respect and prestige ensuring a central part in all people management work. There appears at times some reluctance to devolve case work to line managers and some renegotiation of the powerbase and control within these relationships. As a consequence, contractual and case work in HR departments is increasing, resulting in even less time for strategic HR work.

Furthermore, the research accepts that the human resource environment has changed in response to the role employment regulation plays in formulating "internal rules", but it is also about how law has changed the identity of human resource practitioners. Subsequently, human resource management as a profession has become more strongly embedded in public sector organisations because of the increased need for legal compliance. This is because the level of expertise required to comply with regulation has strengthened their identity and facilitated the development of their knowledge base.

This paper will assist practitioners and learners in understanding the relationship between employment regulation and decision making by taking a contemporary approach in reviewing how strategic human resource management (SHRM) works in practice. The research highlights the practical challenges experienced by senior HR professionals in balancing the strategic needs of the business with the ongoing high volume operational workload. It explores the changing and sometimes conflicting priorities of operational and strategic HR. Practitioners might benefit from the insights offered into how challenges can be overcome and how senior HR professionals prepare themselves for the everchanging requirements of their role.

In addition, organisations may consider how they can prepare their HR staff for internal promotions by increasing the opportunity for exposure to strategic HR work. If HR teams are limited to contractual operational work the organisation is at risk of being ill-prepared for ensuring a pipeline of talent and good practice in people management in a competitive environment.

The role of the human resource professional in terms of operational practices is very important. Further research might explore HR departments in the private sector and compare the experiences to the three case study organisations in this study. The rebranding of the HR role to "legal specialist" might be further explored with a particular emphasis on the rationale for this and the desire for undertaking role negotiation. Power, respect and prestige in the HR profession might be considered, existing and future. 


\section{References}

ACAS,(2013). Employment Law Update. (Online). Available at: http://www.acas.org.uk/index.aspx?articleid=4663 (accessed 12 October 2013).

Andrew, M; Squire, C. and Tamboukou, M. (2008). Doing Narrtaive Research, London: Sage.

Anwaar, M. (2016). “Impact of Firms' Performance on Stock Returns (Evidence from Listed Companies of FTSE-100 Index London, UK)", Global Journal of Management and Business Research: D Accounting and Auditing. 16 (1), 1-10.

Armstrong, M. (2005). Handbook of Human Resource Management, Kogan Page Ltd, London.

Armstrong, M. (2006). A Handbook of Human Resource Management Practice. 10 $0^{\text {th }}$ ed. London: Kogan Page.

Bach, S., Givan, R.K., Forth, J. (2009). “The Public Sector in Transition”, Brown, W. Bryson, A. Forth, J, Whitfield, K. (Eds). The Evolution of the Modern Workplace. Cambridge: Cambridge University Press, 307-331.

Bacon, N. (2003). Human Resource Management and Industrial Relations, Ackers, P. and Wilkinson, A. (eds.) Understanding work and employment - industrial relations in transition. Oxford: Oxford University Press, 71-88.

Boxall, P., Purcell, J. (2008). Strategy and Human Resource Management. Hampshire: Palgrave Macmillan.

Bryman, A., Bell, E. (2007). Business Research Methods. Oxford: Oxford University Press.

Bullough, R. V. (2005). “Teacher vulnerability and teachability: a case study of a mentor and two interns", Teacher Education Quarterly 32(2) 23-39.

Butler, Judith (2007). Gender Trouble: Feminism and the Subversion of Identity. Routledge.

Child, J. (1972). “Organization Structure, Environment, and Performance: The Role of Strategic Choice." Sociology 6, 1-22.

Child, J. (1997). "Information Technology, Organization and the Response to Strategic Challenges." California Management Review, XXX (1),33-50.

Churchard, C. (2012). People Management. (Online). Available at: http://www.peoplemanagement.co.uk/pm/articles/2012/10/equal-pay-case-could-costcouncil-2m-in-compensation.htm (accessed 20 October 2013).

Cooke, F. L. and Saini, D. S. (2010). “Diversity Management in India: A Study of Organizations in Different Ownership Forms and Industrial Sectors", Human Resource Management, 49, 477-500.

Dibben, P., Klerck, G., Wood, G. (2011). Employment Relations: A Critical Approach and International Approach, London: CIPD.

Dickens, L. (2010). Legal Regulation and HR Practice. Presentation to Symposium on Equality and Diversity Issues in the Workplace organised by Oxford Brookes University. Worcester College, Oxford, 17th June 2010.

Dickens, L. (2012). Making Employment Rights Effective: Issues of Enforcement and Compliance in Dickens (Eds). Oxford: Hart Publishing. 
Dickens, L., Hart, M., Jones, M., Weeks, A. (2009). “Why legislation has failed to provide employment protection: a note." British Journal of Industrial Relations, Vol. 20(2), pp257258.

Dobbin, F., Sutton, J. R. (1998). "The Strength of a weak state: the rights revolution and the rise of human resource management divisions", American Journal of Sociology, 104, 2: 441- 76.

Eriksson, P., and Kovalainen, A. (2008). Qualitative Methods in Business Research. London: Sage.

Flood, J. (2011) "The re-landscaping of the legal profession: Large law firms and professional reregulation." Current Sociology 59(4), pp507-529.

Gibbs, G. (2002). Qualitative Data Analysis: Explorations with NVivo. Buckingham: Open University Press.

Guan, Y., Yang, W., Zhou, X., Tian, Z. \& Eves, A. (2016). “Predicting Chinese human resource managers' strategic competence: Roles of identity, career variety, organizational support and career adaptability." Journal of Vocational Behavior 92: 116-124.

Guest, D. (1987a). "Human resource management and performance: a review and a research agenda." International Journal of Human Resource Management, 8(3), pp263-76.

Harris, L. (2009). "Employment law and human resource strategies." in Leopold, J., and Harris, L. (eds.) The Strategic Managing of Human Resources. Harlow: Prentice Hall, pp70 - 95.

Heery, E. (2011a). "Reassessing the Employment Relationship: An Introduction" in Blyton, P., Heery, E., Turnbull, P (eds.) Reassessing the Employment Relationship, Basingstoke: Palgrave Macmillan, 1-17.

Heery, E. (2011b). “Debating employment law: responses to judification” in Blyton, P., Heery, E., and Turnbull, P (eds.) Reassessing the Employment Relationship, Basingstoke: Palgrave Macmillan, 71-97.

Hoor-Ul-Ain, S. (2014). “Business Strategy \& HR: Strange Bedfellows or Strategic Allies?" (A qualitative study to unlock the value of HR as Strategic Business Partner). European Journal of Business and Management, 6. 267-274.

Ibarra, H. (1999). "Provisional Selves: Experimenting with Image and Identity in Professional Adaptation." Administrative Science Quarterly, 44(4), 764-791.

King, N. (2006). "Using Templates" in Cassell, C., and Symon, G (eds.) Essential guide to qualitative methods in organisational research. London: Sage, 256-270.

Kochan, T. A., Katz, H. C., McKersie, R. B. (1986). The transformation of American Industrial Relations. New York: Basic Books.

Kinsey, S. (2012). Professional Partner or Management Bitch: A Discourse Analytic Study of the Identity Construction of HR practitioners in English Local Government. Thesis. Nottingham University.

Kochan, T. A., McKersie, R. B., Cappelli, P. (1984). "Strategic Choice and Industrial Relations Theory" Industrial Relations: A Journal of Economy and Society, 23, 16-39.

Legge, K. (2005). Human Resource Management: Rhetoric and Realities, Palgrave Macmillan.

Losley, M., Meisinger, S. R., Ulrich, D. (2005). "Conclusion: Reality, Impact and Professionalism" Human Resource Management, 44(2), pp201-206.

Loxley, J. (2007). Performativity: the new Critical Idiom. Abindon, Routledge. 
Maddox-Daines, K. (2015). A relational Approach to Female Managers' Identity Construction: Narratives from a case in the UK Higher Education Sector. PhD. University of Essex.

Naznin, H., Hussain, A. (2016). "Strategic Value Contribution Role of HR". Vision: The Journal of Business Perspective, 20, 135-138.

Nicolini, D. (2012). Practice Theory, Work, and Organization. Oxford: Oxford University Press.

Oppong, N. (2018). "Negotiating transparency: NGOs and contentious politics of the Extractive Industries Transparency Initiative in Ghan." Contemporary Social Science, 13:1, 58-71.

Priola, V. (2007). "Being Female Doing Gender. Narratives of Women in Education Managemen." Gender and Education, 19, 21-40.

Saha, N., Aleš G., Petr, S. (2017). “Organizational agility and HRM strategy: Do they really enhance firms' competitiveness?" International Journal of Organizational Leadership [online], 6 (3), 323-334.

Saunders, M., Lewis, P. and Thornhill, A. (2009). Research Methods for Business Students. Pearson, New York.

Schein, E. H (1978). "The Role of the Consultant: Content Expert or Process Facilitator." Journal of Counseling and Development, 56 (7) 22-26.

Sheppard, B., Lewiicki, R., Minton, J. (1992). Organisational Justice. New York: Lexington.

Stanton, N. Salmon, P. M. Walker G. H. and Jenkins, D. P. (2010). "Is situation awareness all in the mind?" Theoretical Issues in Ergonomics Science,11 (2), 29-40.

Taylor, S., Emir, A. (2017). Employment Law: An Introduction. Oxford: Oxford University Press..

Waring, T.W., Wainwright, D. (2008). Innovative developments in the use of Template Analysis: Two comparative case studies from the field. Proceedings of the 7th European Conference on Research Methodology for Business and Management Studies, Regents College, London, UK, 19-20th June, 2008.

Waring, T., Wainwright, D. (2008) ."Issues and Challenges in the Use of Template Analysis: Two Comparative Case Studies from the Field." The Electronic Journal of Business Research Methods. 6 (1).

Watson, T. J. (2006). “The Organisation and Disorganisation of Organisation Studies." Journal of Management Studies, 43 (2).

Watson, T. J. (1977) The Personnel Managers: A Study in the Sociology of Work and Employment. London: Routledge and Kegan.

Weick, K. (2009). Making Sense of the Organization (Volume 2) The Impermanent Organization. London: Blackwell.

Yin, R. K. (2004). The Case Study Anthology. London: Sage. 